\title{
Pubertal height gain is inversely related to peak BMI in childhood
}

\author{
Anton Holmgren 1,2, Aimon Niklasson'1, Andreas F.M. Nierop ${ }^{3}$, Lars Gelander ${ }^{1}$, A. Stefan Aronson², Agneta Sjöberg ${ }^{4}$, \\ Lauren Lissner ${ }^{5}$ and Kerstin Albertsson-Wikland ${ }^{6}$
}

BACKGROUND: Childhood BMI may influence subsequent growth in height as well as the timing of puberty. The aim of the present study was to investigate associations between BMI in childhood and subsequent height gain/pubertal growth.

METHODS: Longitudinal growth data were used (GrowUp ${ }_{1990}$ Gothenburg cohort, $n=1,901$ ). The QEPS growth-model was used to characterize height gain in relation to the highest BMI value between 3.5 and $8 y$ of age. Children were defined as overweight/obese (OwOb) or normal weight/underweight (NwUw), using the 2012 International Obesity Task Force criteria.

RESULTS: A negative association between childhood BMI and pubertal height gain was observed. Already at birth, OwOb children were heavier than NwUw children, and had a greater height velocity during childhood. Onset of puberty was 3.5/3.0 mo earlier in OwOb girls/boys, and they had $2.3 / 3.1 \mathrm{~cm}$ less pubertal height gain from the QEPS-models specific $P$-function than NwUw children. Adult height was not related to childhood BMI.

CONCLUSION: We found that pubertal height gain was inversely related to peak BMI in childhood. Higher childhood $\mathrm{BMI}_{\text {SDS }}$ was associated with more growth before onset of puberty, earlier puberty, and less pubertal height gain, resulting in similar adult heights for OwOb and NwUw children.

$\mathbf{H}$ uman growth is a complex process influenced by both genetic and environmental factors. Secular trends, including longer/heavier newborns, earlier puberty and taller adult heights have been observed during the past $150 \mathrm{y}(1,2)$. These secular changes are related to changing living conditions $(3,4)$, and are suggested to be linked to nutritional factors with increasing weight and BMI during infancy and childhood over time (5). The worldwide epidemic of childhood obesity has enhanced interest in the relationship between childhood BMI and subsequent growth (6). Childhood obesity that persists into adulthood often first manifests between 3 and 8 y of age, a time when height velocity usually is gradually decelerating.
Puberty induces a dramatic change in linear growth with increased height velocity, referred to as the pubertal growth spurt. Description of growth during puberty has been a challenge because previous growth models have not been able to both calculate precisely the specific pubertal growth function and model individualized pubertal growth. The SITAR-model was the first growth model that allowed for individualization of the pubertal growth (7). Another growth model is the Auxal model that in a computerized way can estimate and describe growth divided to childhood and adolescent periods (8). However, neither of these models can separate growth during puberty into different components, nor do they model growth from birth to adult height since fetal/infancy growth is not included. Both the infancy — childhood-puberty (ICP) growth model (9), and the new QEPS growth model (10) include fetal/ infancy growth and thereby model growth from early life to adulthood. Moreover, both models include a specific pubertal component within the total growth curve. In the ICP-model, this pubertal component takes a fixed form, whereas in the QEPS-model it takes an individualized shape-invariant form. The QEPS-model can describe individual patterns of growth in height from birth to adult height, defined by four mathematical functions; a Quadratic $(Q)$ function, mainly representing the childhood component of growth, a negative Exponential $(E)$ function, representing fetal and infancy growth, a Pubertal $(P)$ function, and a Stop $(S)$ function indicating end of linear growth (Figure 1a). The different growth-functions can be modified by both time-scale and height-scale parameters, thus describing individualized growth. The QEPS-model can also mathematically delineate estimates of pubertal growth from the total growth curve and from the specific $P$-function, and also gives estimates for the onset, middle and end of growth during puberty as shown in Figure $\mathbf{1 b}$ (11).

The aim of this study was to investigate the association between peak childhood BMI and subsequent gain in height, in particular the pubertal pattern of growth delineated by the QEPSmodel, using data obtained from the Grow $\mathrm{Up}_{1990}$ Gothenburg

\footnotetext{
'Göteborg Pediatric Growth Research Center (GP-GRC), Department of Pediatrics, Institute of Clinical Sciences, Sahlgrenska Academy, University of Gothenburg, Gothenburg, Sweden; ${ }^{2}$ Department of Pediatrics, Halmstad Hospital, Halmstad, Sweden; ${ }^{3}$ Muvara bv, Multivariate Analysis of Research Data, Leiderdorp, The Netherlands; ${ }^{4}$ Department of Food and Nutrition, and Sport Science, University of Gothenburg, Gothenburg, Sweden; ${ }^{5}$ Section for Epidemiology and Social Medicine (EPSO), Institute of Medicine, Sahlgrenska Academy, University of Gothenburg, Gothenburg, Sweden; ${ }^{6}$ Department of Physiology/Endocrinology, Institute of Neuroscience and Physiology, The Sahlgrenska Academy, University of Gothenburg, Gothenburg, Sweden. Correspondence: Anton Holmgren (anton.holmgren@regionhalland.se) Received 25 May 2016; accepted 20 September 2016; advance online publication 11 January 2017. doi:10.1038/pr.2016.253
} 


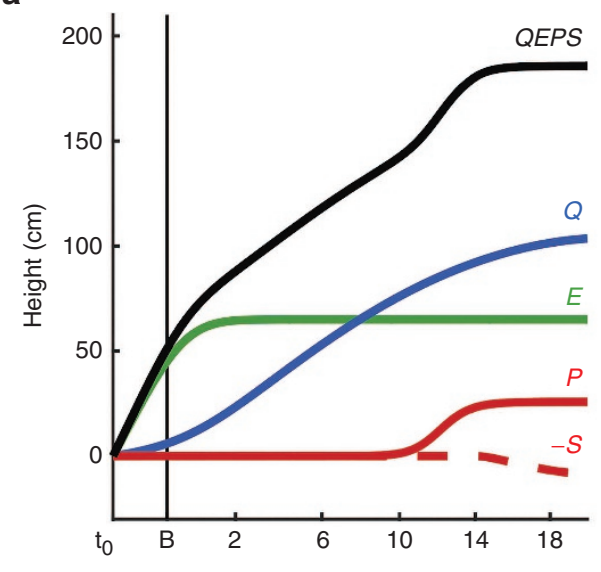

b

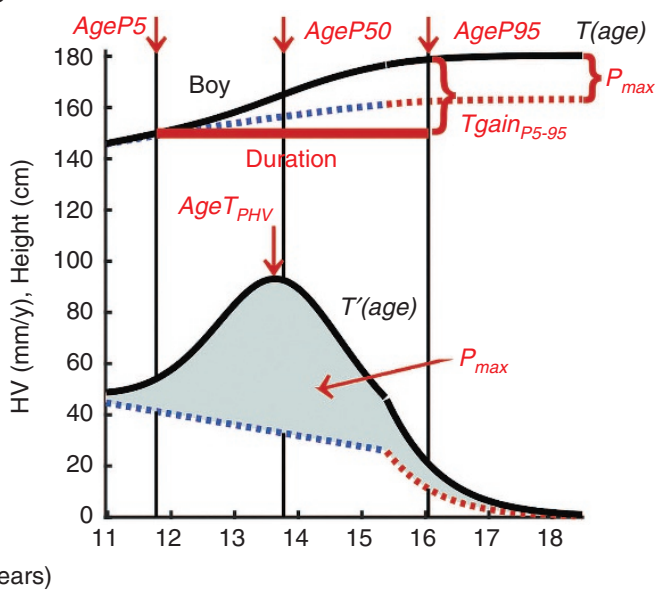

Figure 1. (a) The total height (QEPS) is the sum of four growth functions: Quadratic $(Q)$, Exponential $(E)$, Pubertal $(P)$, and $\operatorname{Stop}(S)$. $B=$ birth, $t_{0}=a b o u t$ 6 wk after conception. Birth is marked with a vertical line. (b) Total height and height velocity estimated by the QEPS-model are shown for an individual. Onset, AgeP5 as age at which 5\% of the $P$-function growth is reached, mid puberty, AgeP50 as age at which 50\% of the $P$-function growth is reached and Age at Peak Height Velocity AgeT $_{P H}$ of the total height function $T$ from the QEPS model is reached and end of pubertal growth, AgeP95 as age at which $95 \%$ of the $P$-function growth is reached are marked with vertical lines. The duration of puberty is shown by the bold horizontal line. The pubertal height gain is shown as the growth from AgeP5 to AgeP95 from the total growth curve ( $\operatorname{Tgain}_{P 5-95}$ ), and from the specific pubertal part (Pmax); both shown at the top of the figure in the height graph and as the marked area in the height velocity graph.

cohort. This was a population based sample of children born around 1990 (12). Preliminary versions of these results have been presented and published in abstracts $(13,14)$.

\section{METHODS}

\section{Study Design}

The GrowUp ${ }_{1990}$ Gothenburg birth cohort was the basis for the present longitudinal study. The independent variable used to assess childhood weight status was based on the highest individual BMI SDS $\left(\mathrm{BMI}_{\mathrm{CDS}}\right)$ between the ages of 3.5-8.0 y for boys and 3-7.0 y for girls. The dependent variables studied were birth-characteristics, growth estimates generated by the QEPS-model, and adult height. The age of $3.5 \mathrm{y}$ as lower age limit for peak BMI was used because BMI levels in infancy undergo rapid changes. The upper limit of $7 \mathrm{y}$ for girls and 8 $\mathrm{y}$ for boys was chosen due to the difference in pubertal timing (1), to ensure that the peak BMI occurred in childhood as opposed to being a reflection of early puberty.

Ethical approval was obtained from the Regional Ethical Review Board in Gothenburg, (Ad 444-08 T062-09), and all participants gave informed consent.

\section{Study Population}

Briefly, the GrowUp ${ }_{1990}$ cohort included 5,314 students, born around 1990; the present study used data from healthy individuals born at full term (gestational age, 37-42 wk) in Sweden, where information on longitudinal growth until adult height was available (12). Weight and height had been measured by experienced nurses at well-baby clinics and at schools in Gothenburg and surrounding municipalities. As part of the GrowUp ${ }_{1990}$ survey, height and weight were collected retrospectively from health records for final-year students in high schools in Gothenburg and the surrounding municipalities in 2008-2009. These measures was undertaken by the trained study team, individuals that seemed to have not reached adult height was then measured yearly until adult height. The study group was selected for the present study using the following steps:

1. Computerized selection of individuals with height/weight measurements registered for each of the following ages; at birth; as an infant from 0 to $9 \mathrm{mo}$ (two or more measurements); as a toddler between 9 mo and $3.5 \mathrm{y}$; as a child from 3.5 to $<6.0 \mathrm{y}$; as a schoolchild; from 6.0 to $<9.0 \mathrm{y}$; as a juvenile from 9.0 to $<12.0 \mathrm{y}$; in adolescence from 12.0 to $<16.0 \mathrm{y}$; and in adulthood $\geq 16 \mathrm{y}$.
2. Visual growth curve analysis to confirm the growth characteristics of the individuals in the study group.

The resulting analytic sample included 1,901 individuals identified by the above mathematical and visual selection (929 female, 972 male). 45,950 measurements were obtained, on average 24 measurements per individual (range 11-36 measurements).

For girls/boys in the analytic sample; birth-length ${ }_{\mathrm{SDS}}$ was $-0.55 /-0.50$, birth-weight ${ }_{\mathrm{SDS}}$ was $-0.19 /-0.23$; and at $18 \mathrm{y}$ of age;

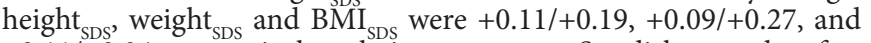
$-0.11 /+0.04$, respectively, relative to current Swedish growth references $(1,15,16)$. As an indication of representativeness of the analytic sample, corresponding values for the entire sample of Nordic origin of the GrowUp ${ }_{1990}$-cohort at 18 y of age $(n=4,790)$ were: height ${ }_{\mathrm{SDS}}$ $+0.05 /+0.14$, weight sDS $+0.09 /+0.23$, and $\mathrm{BMI}_{\mathrm{SDS}}+0.03 /+0.18$ for girls/boys, respectively (12).

\section{Childhood BMI Classification and Calculations}

The International Obesity Task Force (IOTF) BMI classification was used to define subjects as obese $(\mathrm{Ob})$, overweight $(\mathrm{Ow})$, normal weight $(\mathrm{Nw})$, and underweight (Uw), during childhood (17), using crude $\mathrm{BMI}$ values that were transformed to $\mathrm{BMI}_{\mathrm{SDS}}$ to yield age- and gender-specific BMI-scores. For the calculations, we used the highest $\mathrm{BMI}_{\mathrm{SDS}}$ value obtained between 3.5 and $8.0 \mathrm{y}$ for each boy and between 3.5 and 7.0 y for each girl. The $\mathrm{BMI}_{\mathrm{SDS}}$ value for each child was related to different growth estimates from the QEPS-model. The analyses were made both as a continuum of the highest BMI $\mathrm{SDS}_{\text {for }}$ each child, and with the study population divided into OwOb and NwUw subgroups.

\section{The QEPS-Model}

The QEPS-model for individual growth is constructed using a combination of four basic shape-invariant growth functions: a quadratic $Q$-function and a negative exponential $E$-function, both starting during foetal life, 8 mo before birth; the $E$-function levels off after birth, whereas the $Q$-function continues until end of growth (10). A specific nonlinear pubertal $P$-function starts at onset of puberty, and a stop $S$-function ends growth according to both the $Q$-function continuing during puberty and the specific $P$-function. For each function, an individual height-scale parameter is defined, and for the $E$ - and $P$-functions, a time-scale parameter; giving six modifying parameters in total, resulting in a possibility to model individual growth curves. The QEPS-model is also illustrated in Figure 1. 


\section{Articles $\mid$ Holmgren e tal.}

Table 1. Characteristics of the study population, presented as mean (SD), before puberty

\begin{tabular}{|c|c|c|c|c|}
\hline Girls & $\begin{array}{c}\mathbf{O w O b}^{\mathbf{a}}\left(\mathbf{S D}^{\mathbf{b}}\right) \\
\left(n^{\mathrm{e}}=187\right) \text { mean }\end{array}$ & $\begin{array}{c}\mathbf{N w U W}_{\mathbf{c}}^{\mathbf{c}(\mathbf{S D})} \\
(n=742) \text { mean }\end{array}$ & $\begin{array}{l}\text { Difference } \\
\left(95 \% \mathrm{Cl}^{d}\right)\end{array}$ & $\begin{array}{l}\text { P value } \\
\text { (T-test) }\end{array}$ \\
\hline \multicolumn{5}{|l|}{ At birth } \\
\hline Birth weight (g) & $3,712(569)$ & $3,491(473)$ & $221(40-494)$ & $<0.001$ \\
\hline Birth length $(\mathrm{cm})$ & $50.43(2.03)$ & $49.98(2.09)$ & $0.45(0.12-0.78)$ & 0.0085 \\
\hline Gestational age (days) & $281.9(8.90)$ & $281.0(9.26)$ & $0.87(-0.61-2.34)$ & 0.2475 \\
\hline Max value of Q-function (cm) & $101.15(8.12)$ & $97.77(7.65)$ & $3.38(2.14-4.63)$ & $<0.001$ \\
\hline Boys & $\begin{array}{c}\text { OwOb (SD) } \\
(n=190) \text { mean }\end{array}$ & $\begin{array}{c}\text { NwUw (SD) } \\
(n=782) \text { mean }\end{array}$ & $\begin{array}{l}\text { Difference } \\
(95 \% \mathrm{Cl})\end{array}$ & $\begin{array}{l}P \text {-value } \\
\text { ( } T \text {-test) }\end{array}$ \\
\hline \multicolumn{5}{|l|}{ At birth } \\
\hline \multicolumn{5}{|l|}{ Infancy/childhood } \\
\hline Max value of E-function (cm) & $65.16(2.85)$ & $65.03(2.65)$ & $0.13(-0.30-0.55)$ & 0.5562 \\
\hline Max value of $\mathrm{Q}$-function $(\mathrm{cm})$ & $108.81(8.00)$ & $104.57(7.45)$ & $4.24(3.036-5.44)$ & $<0.001$ \\
\hline
\end{tabular}

\section{Statistical Analysis and Visual Growth Data Evaluation}

To construct longitudinal growth charts for each individual, data files were exported to Matlab, and visual data verification was performed (The MathWorks, Natick, MA, v.7.13.0R2012b). Student's two tailed $t$-test was used to compare birth characteristics, growth estimates from the QEPS-model and adult heights for weight status dichotomized into the $\mathrm{OwOb}$ - and NwUw-groups. Statistical analyses were performed using SAS software (SAS Institute, Cary, NC, Version9.3). A $P$ value $<0.05$ was considered statistically significant.

\section{RESULTS}

\section{Description of the Study Population}

Of the 929 girls, $3.7 \%$ were obese, $16.4 \%$ overweight, $75.8 \%$ had a normal weight, and $4.1 \%$ were underweight. For the 972 boys, the corresponding proportions were $3.2,16.3,78.0$, and $2.5 \%$, respectively. The highest individual $\mathrm{BMI}^{\mathrm{SDS}}$ recorded were evenly distributed over the whole age span, 3.5-7.0/3.5$8.0 \mathrm{y}$ for girls/boys.

\section{Early and Prepubertal Growth vs. Childhood BMI}

At birth, there were significant differences between the children who later became overweight/obese compared with the remaining group with lower BMIs; girls/boys in the ObOwgroup were $221 / 122 \mathrm{~g}$ heavier $\left(+0.42 / 0.23 \mathrm{BMI}_{\mathrm{SDS}}\right)$ than the NwUw-group (Table 1). Childhood $\mathrm{BMI}_{\mathrm{SDS}}$ was not related to the fetal/infancy exponential $(E)$ component of growth, (Emax). Both girls and boys in the OwOb-group had significantly more prepubertal growth due to the $Q$-function than those in the NwUw-group, with higher Qmax related to higher $\mathrm{BMI}_{\mathrm{SDS}}$ in a linear correlation (Figure 2).

\section{Pattern of Pubertal Growth vs. Childhood BMI}

Onset of the pubertal growth, defined as age at which $5 \%$ of the $P$-function growth is reached (AgeP5) for girls/boys was
3.5/2.5 mo earlier in the $\mathrm{OwOb}$ than the NwUw-group. Midpuberty, defined as age at which $50 \%$ of the $P$-function growth is reached (AgeP50) and the estimated end of pubertal growth, as age at which $95 \%$ of the $P$-function growth is reached

(AgeP95) were both 3.5 mo earlier for girls in the $\mathrm{OwOb}$ than the NwUw-group; for boys, mid-puberty was 3.0 and end of puberty 3.5 mo earlier in the $\mathrm{OwOb}$ than the NwUw-group (Table 2). For boys, the duration of puberty differed between the two groups; the duration was approximately 1 mo shorter for the $\mathrm{OwOb}$ - than the $\mathrm{NwUw}$-boys $(P<0.001)$ (Table 2). There was no such relationship for girls $(P=0.79)$.

\section{Pubertal Gain and Adult Height vs. Childhood BMI}

The specific pubertal gain as Pmax was inversely related to the individual $\mathrm{BMI}_{\mathrm{SDS}}$ in childhood $(P<0.001)$ across the whole BMI spectrum (Figure 3 ). When comparing the Ob-subgroup with the Nw-group, Pmax was $3.9 / 5.2 \mathrm{~cm}$ less for obese girls/ boys than their normal weight counterparts (Figure 3 ). The pubertal gain estimate from the total growth curve was lower in the OwOb-group than the $\mathrm{NwUw}$-group, particularly for boys; but the difference was smaller than that observed for the specific pubertal gain (Table 2). There was no significant difference in adult height related to BMI in childhood due to the counteraction of Qmax and Pmax (Table 2, Figure 2 and Figure 3).

\section{DISCUSSION}

To our knowledge, this is the first study to investigate the whole pattern of pubertal growth in relation to peak BMI in childhood. The onset, middle, end and duration of pubertal growth, including both the specific and the total pubertal gain have been investigated with the QEPS-model (10). As the study is based on a relatively large cohort, with longitudinal 


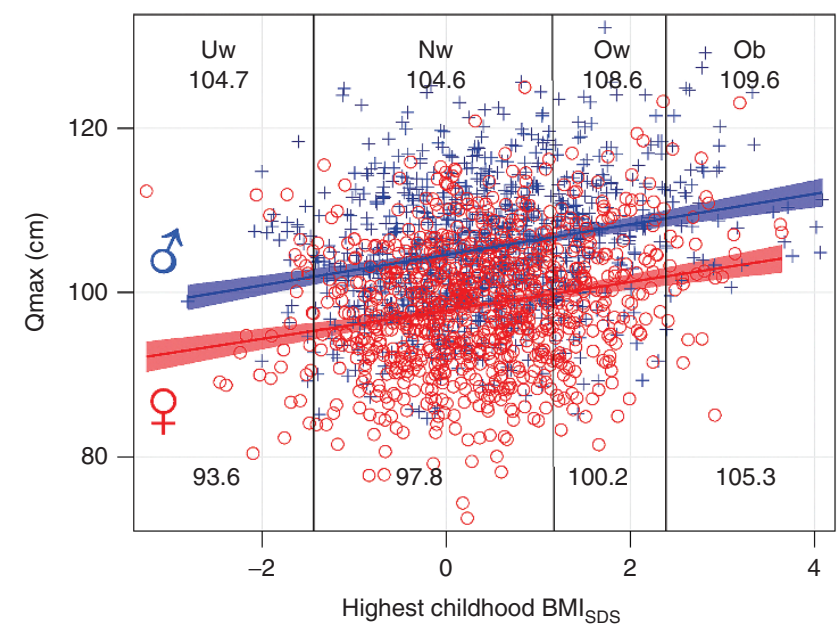

Figure 2. The gain in adult height in $\mathrm{cm}$ due to $Q$-function growth, $Q \max$ is related to the highest $\mathrm{BMI}_{\mathrm{SDS}}$ for each girl (red circles) and boy (blue cross). $\mathrm{BMI}_{\mathrm{SDS}}$ for underweight (below -1.51 to -1.29), overweight (above 1.15-1.52) and obesity (above 2.21-2.30) are marked with approximate vertical lines (17). The mean values of $Q \max (\mathrm{cm})$ are shown in the bottom (girls) and top (boys). For girls; $Q \max =97.47+1.90 \times \mathrm{BMI}_{\mathrm{SDS}}$, adjusted $\mathrm{r}^{2}=$ 0.0457 . For boys; $Q \max =104.32+2.02 \times \mathrm{BMI}_{\mathrm{SDS}^{\prime}}$, adjusted $\mathrm{r}^{2}=0.0487$.

data obtained in a community based setting including different socio-demographic areas, the results are likely to be generalizable. Results showed that there was an inverse relationship between the highest childhood BMI and the specific pubertal gain across the entire BMI spectrum. Thus, overweight/obese children grew less during puberty, estimated both as pubertal gain from the specific pubertal growth function $(P)$ and as total growth during the pubertal years, compared with their normal/underweight peers. At birth, children who went on to become $\mathrm{OwOb}$ were already heavier than their $\mathrm{NwUw}$ counterparts, and thereafter gained more height, as shown by a high Q-function. The onset of pubertal growth was earlier for both genders in the $\mathrm{OwOb}$ compared with the $\mathrm{NwUw}$-group. However, adult height was not related to BMI in childhood as the high $Q$-function and the low $P$-function for $\mathrm{OwOb}$ children canceled each other out.

The Q-function of the QEPS-model was found to be significantly higher in the OwOb-group, reflecting more childhood growth. Results also showed a linear regression over the whole BMI-range, implying the existence of physiological mechanism(s) regulating the relationship between weight and height-velocity in childhood.

In 1927, Keller stated that obese children often were taller than normal-weight children during childhood, and it was subsequently shown that being overweight during infancy/ childhood was associated with increased height velocity in childhood, with opposite findings for underweight children (18). The growth study based on the GrowUp ${ }_{1974}$ Gothenburgbirth cohort found somewhat similar results; a greater increase in BMI from 2-8 y of age was associated with a taller stature at 8 y (19). Our study also confirmed results from many studies tracking childhood obesity back to birth $(20,21)$, with significant differences in birth-weight between children who went on to have higher BMIs during childhood compared with children with BMIs in the normal/underweight range.

Many factors, both genetic and environmental, are known to be associated with onset of puberty (5). In our study, the onset of puberty (estimated as AgeP5) was significantly earlier in the OwOb-group compared with the NwUw-group for both genders. Numerous studies have shown an association between obesity and early puberty for girls, and in 1974 the "critical fat mass theory" postulated that the initiation of female puberty is dependent on a certain amount of body fat (22). Large American (23,24), Danish (25), and Dutch (26) cross-sectional studies found that high BMI in childhood was associated with earlier puberty in girls. Linear correlations over the entire BMI range, was also found in a recent study based on an American cohort, showing an inverse association between $\mathrm{BMI}_{\mathrm{SDS}}$ in childhood and age at pubarche and menarche (27).

For boys, the associations between childhood weight and onset of puberty have been ambiguous, probably due to differences in both study groups and definitions of puberty. In 1901, Frölich noted that obesity in a boy was associated with late pubertal development (18). This finding was later supported by American studies where normal-weight boys were more likely to have earlier gonadal maturation than overweight/obese boys $(23,28)$. A German study found no correlation between BMI and pubertal timing when investigating BMI 1-2 y before pubertal height acceleration (29). However, most other non-American studies support our findings, with earlier onset of puberty in overweight/ obese boys; in the 1940s, under-nutrition was reported to delay onset of puberty and Mossberg found earlier puberty in obese Swedish boys. These findings were confirmed in the United Kingdom (18), and later in many European counties (19,25,30), and Japan (31). Correlation between BMI and mid-puberty was also seen for boys in a UK study, which found a linear correlation between $\mathrm{BMI}_{\mathrm{SDS}}$ in childhood and age at PHV (30).

Results from the present study showed that growth related to the $P$-function (Pmax), was reduced in the OwOb-group and showed a negative linear correlation with the highest childhood BMI, over the entire BMI-range. This finding confirms earlier reports of declining differences in observed height between overweight/obese and normal-weight/underweight subjects during the adolescent period $(30,32)$. The previous study using the Grow $\mathrm{Up}_{1974}$ Gothenburg cohort found earlier onset of puberty and reduced height gain during adolescence to be related to increased childhood BMI (19). However, the methodological approach used was different; that study focused on BMI change.

We are not aware of any other studies investigating the association between childhood BMI and the duration of the total pubertal growth. Theoretically, one may suppose that a high weight gain in childhood affects maturation with a more rapid pubertal process. This was evident only for boys in the present study, with a significant shorter duration of pubertal growth for OwOb-than NwUw-boys. Buyken et al. showed an association between BMI in juvenility and a shorter duration from onset of the pubertal growth spurt to $\mathrm{PHV}$, for both OwOb-boys and girls (29). The present study showed no significant difference 


\section{Articles | Holmgren et al.}

Table 2. Pubertal growth estimates and adult height of the study population

\begin{tabular}{|c|c|c|c|c|}
\hline Girls & $\begin{array}{c}\mathbf{O w O b}^{\mathbf{a}}(\mathbf{S D}) \\
\left(n^{\mathrm{e}}=187\right) \text { mean }\end{array}$ & 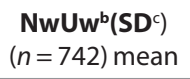 & $\begin{array}{l}\text { Difference } \\
\left(95 \% \mathrm{Cl}^{d}\right)\end{array}$ & $\begin{array}{l}P \text {-value } \\
\text { ( } T \text {-test) }\end{array}$ \\
\hline \multicolumn{5}{|l|}{ Onset of puberty } \\
\hline Age at $5 \%$ of the pubertal growth (years) & $9.54(1.05)$ & $9.83(0.98)$ & $-0.29(-0.45--0.13)$ & $<0.001$ \\
\hline Height at $5 \%$ of the pubertal growth $(\mathrm{cm})$ & $140.4(7.56)$ & $139.5(6.89)$ & $0.91(0.22-2.04)$ & 0.115 \\
\hline \multicolumn{5}{|l|}{ Mid puberty } \\
\hline Age at $50 \%$ of the pubertal growth (years) & $11.77(1.04)$ & $12.06(0.98)$ & $-0.29(-0.45--0.13)$ & $<0.001$ \\
\hline Age at peak height velocity (years) & $11.49(1.05)$ & $11.81(0.98)$ & $-0.32(-0.49--0.16)$ & $<0.001$ \\
\hline \multicolumn{5}{|l|}{ End of puberty } \\
\hline Age at $95 \%$ of the pubertal growth (years) & $14.33(1.04)$ & $14.62(0.99)$ & $-0.29(-0.45--0.13)$ & $<0.001$ \\
\hline Height at $95 \%$ of the pubertal growth $(\mathrm{cm})$ & $166.4(6.30)$ & $166.4(6.34)$ & $0.019(-1.00-1.04)$ & 0.971 \\
\hline \multicolumn{5}{|l|}{ Pubertal gain } \\
\hline Max pubertal growth function (cm) & $11.16(3.81)$ & $13.42(3.48)$ & $-2.26(-2.83--1.69)$ & $<0.001$ \\
\hline $\begin{array}{l}\text { Growth in } \mathrm{cm} \text { from heights at } 5 \% \text { to } 95 \% \text { of } \\
\text { the pubertal growth }\end{array}$ & $26.05(3.99)$ & $26.94(3.62)$ & $-0.89(-1.48--0.29)$ & $<0.001$ \\
\hline Adult height (cm) & $168.2(6.28)$ & $168.3(6.37)$ & $-0.037(-1.06-0.98)$ & 0.943 \\
\hline Boys & $\begin{array}{c}\text { OwOb (SD) } \\
(n=190) \text { mean }\end{array}$ & $\begin{array}{c}\text { NwUw (SD) } \\
(n=782) \text { mean }\end{array}$ & $\begin{array}{l}\text { Difference } \\
(95 \% \mathrm{Cl})\end{array}$ & $\begin{array}{l}P \text {-value } \\
\text { (T-test) }\end{array}$ \\
\hline \multicolumn{5}{|l|}{ Onset of puberty } \\
\hline Age at $5 \%$ of the pubertal growth (years) & $11.58(0.96)$ & $11.79(0.97)$ & $-0.21(-0.36--0.057)$ & 0.0070 \\
\hline Height at $5 \%$ of the pubertal growth $(\mathrm{cm})$ & $152.7(7.20)$ & $150.2(6.64)$ & $2.48(1.41-3.55)$ & $<0.001$ \\
\hline Height at $95 \%$ of the pubertal growth $(\mathrm{cm})$ & $180.1(7.04)$ & $179.7(6.39)$ & $0.39(-0.64-1.43)$ & 0.451 \\
\hline \multicolumn{5}{|l|}{ Duration of puberty } \\
\hline $\begin{array}{l}\text { Duration in years between } 5 \% \text { and } 95 \% \text { of } \\
\text { the pubertal growth }\end{array}$ & $4.24(0.21)$ & $4.32(0.21)$ & $-0.077(-0.11--0.044)$ & $<0.001$ \\
\hline \multicolumn{5}{|l|}{ Pubertal gain } \\
\hline Max pubertal growth function $(\mathrm{cm})$ & $14.67(3.79)$ & $17.80(3.52)$ & $-3.13(-3.70--2.56)$ & $<0.001$ \\
\hline $\begin{array}{l}\text { Growth in } \mathrm{cm} \text { from heights at } 5 \% \text { to } 95 \% \text { of } \\
\text { the pubertal growth }\end{array}$ & $27.38(3.71)$ & $29.46(3.67)$ & $-2.08(-2.67--1.50)$ & $<0.001$ \\
\hline Adult height $(\mathrm{cm})$ & $181.9(7.10)$ & $181.6(6.44)$ & $0.29(-0.76-1.33)$ & 0.590 \\
\hline
\end{tabular}

averweight and obese. 'bSD. cNormal and underweight by the 2012 International Obesity Task Force criteria, based on the highest individual BMI ${ }_{\text {sos }}$ between 3.5 and 7.0 y for girls and 3.5 and 8.0 y for boys. ${ }^{d}$ Confidence interval. eNumber of individuals.

in adult height related to childhood BMI, in accordance with other studies $(19,32)$. This was because the high growth associated with the $Q$-function in $\mathrm{OwOb}$-children was compensated for by low growth associated with the $P$-function.

Despite the fact that $\mathrm{OwOb}$-children are taller during childhood than NwUw-children, it is known that obese children secrete low amounts of GH (33). This is believed to be due to the operation of negative feed-back mechanisms that arise owing to elevated IGF1 levels (33). High insulin levels downregulates sex hormone-binding globulin production, which increases bioavailable estrogen, and activate gonadotropin secretion (34). Furthermore, obese children, with high fat mass, have higher leptin levels (35). Leptin serves as a permissive factor for the onset of puberty, providing a link between 


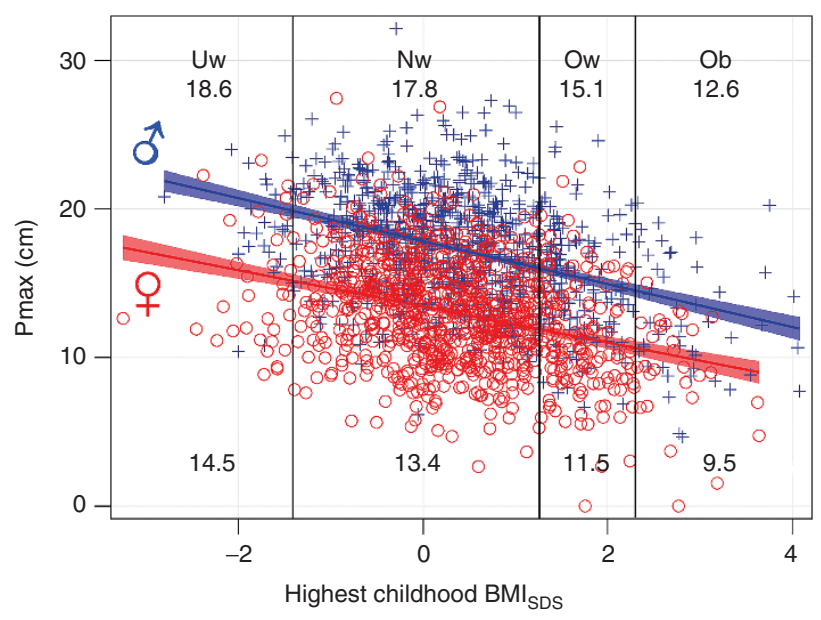

Figure 3. The specific pubertal gain in adult height in $\mathrm{cm}$ due to $P$-function growth, Pmax is related to the highest $\mathrm{BMI}_{\mathrm{SDS}}$ for each girl (red circles) and boy (blue cross). $\mathrm{BMI}_{\mathrm{SDS}}$ for underweight (below -1.51 to -1.29 ), overweight (above $1.15-1.52$ ) and obesity (2.21-2.30) are marked with approximate vertical lines (17). The mean values of $P \max (\mathrm{cm})$ are shown in the bottom (girls) and top (boys). For girls; $P \max =13.66-1.35 \times \mathrm{BMI}_{\mathrm{SDS}}$, adjusted $\mathrm{r}^{2}=0.1074$. For boys; $P \max =$ $18.05-1.61 \times \mathrm{BMI}_{\mathrm{SDS}}$, adjusted $\mathrm{r}^{2}=0.1312$.

obesity and earlier puberty (36). For girls inhibin B, secreted from the ovaries, may also be a marker for the onset of puberty. The mechanisms are not well understood and surprisingly a recent study found an inverse correlation between elevation of inhibin B and overweight (37). Hormonal changes during early/mid puberty are characterized by increasing $\mathrm{GH}$-levels (38). The low GH-levels in overweight/obese individuals may result in $\mathrm{GH}$-levels that are too low to ensure optimal pubertal growth. A somewhat similar combination of low GH-levels, early puberty, low pubertal height gain, and obesity was also seen after cerebral radiation in acute lymphatic leukemia, due to damage of GH-releasing-hormone neurons $(39,40)$.

A possible explanation of the contrasting results concerning onset of puberty for boys in previous studies may be a nonlinear correlation between childhood BMI and onset of male puberty (41). Moderate over-nutrition/being overweight may accelerate linear growth and facilitate the pituitary-driven onset of puberty, whereas being obese may have inhibitory effects on the initiation of puberty through elevated estrogen levels. It is known that obese adult men may have hypogonadotropic hypogonadism, possibly related to increased aromatization of estrogens in fat mass (42). The high prevalence of childhood obesity in the United States, with higher proportions of obese relative to overweight children in OwOb-groups compared with other populations, may lead to dominance of this kind of effect. A recent cross-sectional study by Lee et al. (43), based on gonadal maturation, supports this theory; they found earlier puberty for overweight compared with normal-weight boys, but later puberty for obese compared with overweight boys. Another reason for the mixed results in previous studies could be that it is more difficult to assess gonadal maturation by visual inspection in obese boys.

One limitation of the current study is the use of BMI as the measure, there is not always a correlation between BMI and fat mass at the individual level; high BMI may also be influenced by high bone/muscle-mass. We also have a limited number of obese children in the sample, since it was population-based. This study, with its focus on the pattern of growth, lacks information about hormones and gonadal maturation, the two other main factors used to define puberty. Finally, it is possible that the exclusion of children without complete growth data may reduce the generalizability of the results. However, no major difference was seen in comparison to mean BMI-values in the full sample of the study population.

To conclude, this is the first study showing that childhood BMI is inversely associated with the pubertal height gain with a linear correlation across the entire BMI-range. The QEPS-model has been shown to be a useful tool with which to investigate the pattern of growth. As there was substantially more prepubertal growth, related to the $Q$-function in children with higher childhood $\mathrm{BMI}_{\mathrm{SDS}}$, the resulting adult height was not related to BMI. In both girls and boys, higher childhood BMI, was associated with earlier onset of pubertal growth. The results of this study are potentially useful both for monitoring growth in the population, and for clinical assessments of growth in individual children.

\section{ACKNOWLEDGMENTS}

The authors are thankful to all participants, to the study team lead by Carola Pfeiffer Mosesson and Annika Olsson and to Harriet Crofts for valuable language editing.

\section{STATEMENT OF FINANCIAL SUPPORT}

The authors acknowledge financial support from the Swedish Research Council (7509 and VR 2006-7777); the Swedish Council Formas; the Swedish Research Council for Working Life and Social Research (2006-1624); Pfizer $A B$; the Governmental Grants for University Hospital Research (ALF) from RegionVästra Götaland; PhD-grants from the Southern Swedish healthcare region; the R\&D department, County of Halland; and the Foundation Växthuset for children.

Disclosure: A.F.M.N. works for Muvara, Multivariate Analysis of Research Data, Statistical Consultation, The Netherlands. A.H., A.N., L.G., A.S.A., A.S., L.L., and K.A.W. declare that they have no competing interests.

\section{REFERENCES}

1. Wikland KA, Luo ZC, Niklasson A, Karlberg J. Swedish population-based longitudinal reference values from birth to 18 years of age for height, weight and head circumference. Acta Paediatr 2002;91:739-54.

2. Cole TJ. Secular trends in growth. The Proceedings of the Nutrition Society 2000;59:317-24.

3. Schoch T, Staub K, Pfister C. Social inequality and the biological standard of living: an anthropometric analysis of Swiss conscription data, 18751950. Econ Hum Biol 2012;10:154-73.

4. Alberman E, Filakti H, Williams S, Evans SJ, Emanuel I. Early influences on the secular change in adult height between the parents and children of the 1958 birth cohort. Ann Hum Biol 1991;18:127-36.

5. Parent AS, Teilmann G, Juul A, Skakkebaek NE, Toppari J, Bourguignon JP. The timing of normal puberty and the age limits of sexual precocity: variations around the world, secular trends, and changes after migration. Endocr Rev 2003;24:668-93.

6. Wang Y, Lobstein T. Worldwide trends in childhood overweight and obesity. Int J Pediatr Obes 2006;1:11-25.

7. Cole TJ, Donaldson MD, Ben-Shlomo Y. SITAR-a useful instrument for growth curve analysis. Int J Epidemiol 2010;39:1558-66.

8. Hauspie R, Molinari L. Parametric models for postnatal growth. In: Hauspie R CN, Molinari L, eds. Methods in Human Growth Research. Cambridge: Cambridge University Press; 2004:205-33.

9. Karlberg J. A biologically-oriented mathematical model (ICP) for human growth. Acta Paediatr Scand Suppl 1989;350:70-94. 


\section{Articles | Holmgren et al.}

10. Nierop AF, Niklasson A, Holmgren A, Gelander L, Rosberg S, AlbertssonWikland K. Modelling individual longitudinal human growth from fetal to adult life - QEPS I. J Theor Biol 2016;406:143-65.

11. Holmgren A, Niklasson A, Gelander L, Aronson S, Albertsson-Wikland K. New Puberty growth model for estimation of age for peak height velocity compared with a manual method. Hormone research in paediatrics 2013;80:177.

12. Sjöberg A, Barrenäs ML, Brann E, et al. Body size and lifestyle in an urban population entering adulthood: the 'Grow up Gothenburg' study. Acta Paediatr 2012;101:964-72.

13. Holmgren A, Nierop AFM, Gelander L, et al. Higher childhood BMI is associated with less pubertal gain Obes Facts. The European Journal of Obesity 2015;8 33-4.

14. Holmgren A, Nierop AFM, Gelander L, et al. The pubertal gain in height is inversely related to BMI in childhood. Horm Res Paediatr 2015;84:268-69.

15. Karlberg J, Luo ZC, Albertsson-Wikland K. Body mass index reference values (mean and SD) for Swedish children. Acta Paediatr 2001;90:1427-34.

16. Niklasson A, Albertsson-Wikland K. Continuous growth reference from $24^{\text {th }}$ week of gestation to 24 months by gender. BMC Pediatr 2008;8:8.

17. Cole TJ, Lobstein T. Extended international (IOTF) body mass index cutoffs for thinness, overweight and obesity. Pediatr Obes 2012;7:284-94.

18. WOLFF OH. Obesity in childhood; a study of the birth weight, the height, and the onset of puberty. Q J Med 1955;24:109-23.

19. He Q, Karlberg J. Bmi in childhood and its association with height gain, timing of puberty, and final height. Pediatr Res 2001;49:244-51.

20. Bauer J. Einige Bemerkungen uber "Fettkinder". Med Welt 1929;3:1467.

21. Eriksson J, Forsén T, Osmond C, Barker D. Obesity from cradle to grave. Int J Obes Relat Metab Disord 2003;27:722-7.

22. Frisch RE, McArthur JW. Menstrual cycles: fatness as a determinant of minimum weight for height necessary for their maintenance or onset. Science 1974;185:949-51.

23. Wang Y. Is obesity associated with early sexual maturation? A comparison of the association in American boys versus girls. Pediatrics 2002;110:903-10.

24. Kaplowitz PB, Slora EJ, Wasserman RC, Pedlow SE, Herman-Giddens ME. Earlier onset of puberty in girls: relation to increased body mass index and race. Pediatrics 2001;108:347-53.

25. Aksglaede L, Juul A, Olsen LW, Sørensen TI. Age at puberty and the emerging obesity epidemic. PLoS One 2009;4:e8450.

26. Fredriks AM, van Buuren S, Burgmeijer RJ, et al. Continuing positive secular growth change in The Netherlands 1955-1997. Pediatr Res 2000;47:316-23.

27. German A, Shmoish M, Hochberg Z. Predicting pubertal development by infantile and childhood height, BMI, and adiposity rebound. Pediatr Res 2015;78:445-50.

28. Lee JM, Kaciroti N, Appugliese D, Corwyn RF, Bradley RH, Lumeng JC. Body mass index and timing of pubertal initiation in boys. Arch Pediatr Adolesc Med 2010;164:139-44.
29. Buyken AE, Karaolis-Danckert N, Remer T. Association of prepubertal body composition in healthy girls and boys with the timing of early and late pubertal markers. Am J Clin Nutr 2009;89:221-30.

30. Sandhu J, Ben-Shlomo Y, Cole TJ, Holly J, Davey Smith G. The impact of childhood body mass index on timing of puberty, adult stature and obesity: a follow-up study based on adolescent anthropometry recorded at Christ's Hospital (1936-1964). Int J Obes (Lond) 2006;30:14-22.

31. Yokoya M, Higuchi Y. Geographical differences in the population-based cross-sectional growth curve and age at peak height velocity with respect to the prevalence rate of overweight in Japanese children. Int J Pediatr 2014;2014:867890.

32. Stovitz SD, Demerath EW, Hannan PJ, Lytle LA, Himes JH. Growing into obesity: patterns of height growth in those who become normal weight, overweight, or obese as young adults. Am J Hum Biol 2011;23:635-41.

33. Ballerini MG, Ropelato MG, Domené HM, Pennisi P, Heinrich JJ, Jasper HG. Differential impact of simple childhood obesity on the components of the growth hormone-insulin-like growth factor (IGF)-IGF binding proteins axis. J Pediatr Endocrinol Metab 2004;17:749-57.

34. Kalme T, Koistinen H, Loukovaara M, Koistinen R, Leinonen P. Comparative studies on the regulation of insulin-like growth factor-binding protein-1 (IGFBP-1) and sex hormone-binding globulin (SHBG) production by insulin and insulin-like growth factors in human hepatoma cells. J Steroid Biochem Mol Biol 2003;86:197-200.

35. Argente J, Barrios V, Chowen JA, Sinha MK, Considine RV. Leptin plasma levels in healthy Spanish children and adolescents, children with obesity, and adolescents with anorexia nervosa and bulimia nervosa. J Pediatr 1997;131: 833-8.

36. Marcovecchio ML, Chiarelli F. Obesity and growth during childhood and puberty. World Rev Nutr Diet 2013;106:135-41.

37. Addo OY, Miller BS, Lee PA, Hediger ML, Himes JH. Age at hormonal onset of puberty based on luteinizing hormone, inhibin B, and body composition in preadolescent U.S. girls. Pediatr Res 2014;76:564-70.

38. Albertsson-Wikland K, Rosberg S, Karlberg J, Groth T. Analysis of 24-hour growth hormone profiles in healthy boys and girls of normal stature: relation to puberty. J Clin Endocrinol Metab 1994;78:1195-201.

39. Iughetti L, Bruzzi P, Predieri B, Paolucci P. Obesity in patients with acute lymphoblastic leukemia in childhood. Ital J Pediatr 2012;38:4.

40. Moëll C, Garwicz S, Westgren U, Wiebe T, Albertsson-Wikland K. Suppressed spontaneous secretion of growth hormone in girls after treatment for acute lymphoblastic leukaemia. Arch Dis Child 1989;64:252-8.

41. Tinggaard J, Mieritz MG, Sørensen K, et al. The physiology and timing of male puberty. Curr Opin Endocrinol Diabetes Obes 2012;19:197-203.

42. Hammoud AO, Gibson M, Peterson CM, Hamilton BD, Carrell DT. Obesity and male reproductive potential. J Androl 2006;27:619-26.

43. Lee JM, Wasserman R, Kaciroti N, et al. Timing of puberty in overweight versus obese boys. Pediatrics 2016;137:e20150164. 